\title{
Research on Operating Performance of Small-Sized Retailers-Case Study of City S Market
}

\author{
Jihua Zhang \\ Management School, Jinan University, Guangzhou, China \\ Email: jihuazh@126.com
}

Received 2 April 2015; accepted 22 April 2015; published 23 April 2015

Copyright (C) 2015 by author and Scientific Research Publishing Inc.

This work is licensed under the Creative Commons Attribution International License (CC BY). http://creativecommons.org/licenses/by/4.0/

(c) (i) Open Access

\begin{abstract}
Previous studies have shown that small-sized retailers have weak competitiveness. This paper is intended to explore why they can survive in the market for a long time. It is proven that compared with large chain retailers, small-sized retailers are advantageous in employee utilization and gross margin despite of their weakness in commodity purchase and space utilization. Previous studies also reveal that small-sized retailers are significantly fewer in commercially developed regions than commercially underdeveloped regions, suggesting that it becomes harder for smallsized retailers to survive in the market along with gradual improvement of commercial facilities.
\end{abstract}

Keywords

Retailer, Operating Performance, Buyer Power, Information Sharing, Operational Efficiency

\section{Introduction}

Retailers refer to the middlemen who sell commodities directly to end users, playing the role of bridging manufacture, wholesaler and consumer and constituting the last link of consumers goods supply chain. Small-sized retailers mentioned here refer to the retailers of small scale or slight chain-orientation. It is generally believed that a retailer would become competitive only if it grows to a certain scale. The reason lies in that large retailers with buyer power tend to dominate supply chain procurement negotiations, so they will certainly transfer cost and risk to upstream suppliers in order to cut down procurement cost and improve business performance. On the contrary, small-sized retailers are at a disadvantage in competition in terms of both buyer power and supply chain efficiency, so they are perceived as an outdated business model that is doomed to be eliminated in market competition. 
However, the authors find through survey that a considerable amount of small-sized retailers exist even in first-tier cities. Why do these shops that are theoretically less competitive exist for long? Bearing this question in mind, we visited many relevant governmental agencies in City S, such as the Development and Reform Commission, the Economy, Trade and Information Commission, the Statistical Bureau and the Administration of Industry and Commerce, to acquire abundant secondary data after launching this study in Jun, 2014. As there are considerable literatures on chain retailers, we focus on scattered sale terminals, namely, the retailers of small scale or slight chain-orientation.

\section{Literature Review}

As reported by researchers at home and abroad, there are an array of factors underlying the business performance and competitive strength of a retailer, such as procurement and inventory policy, product and service portfolios, promotion policy, degree of trust on suppliers and information sharing mechanism, etc.

\subsection{Enterprise Competitiveness}

Enterprise competitiveness is an enterprise' overall quality in outperforming other enterprises to provide products and services in a more effective manner in a competitive and open market for purpose of profit-making and self-development. It is a reflection of the enterprise's comprehensive advantage in product, management, technology and culture based on its core resources, and also the enterprise's ability to differentiate itself from rivals in the course of operation and to generate excess profits. Retail businesses have built up certain brand advantage and customer loyalty in business activities for long. A retail business shows its innovation ability and corporate culture in the course of marketing, thus driving the enterprise towards sustainable development.

Jin Bei established an index system for competitiveness evaluation of household appliance retail chain enterprises from the perspectives of scale competitiveness, management competitiveness and expansion competitiveness [1]. Hu Ying-qiong summarizes the factors underlying a retail business's competitiveness through statistical analysis as debt-paying ability, operational safety, income distribution, goods flow, cash flow and scale expansion [2]. Zhang Fang identified the components of a retail business's competitiveness from two levels, including corporate culture, human resources, location, supply chain, commodities, services, marketing and corporate reputation, etc. [3].

\subsection{Retail Market Structure and Buyer Power}

Market structure refers to the intrinsic relations among and features of all elements in a market, including the relation among suppliers, among demanders, between suppliers and demanders and between existing suppliers/ demanders and new suppliers/demanders. Bain establishes the typical theoretical framework of "market structure-conduct-performance”, holding that market performance is jointly determined by market structure and conduct [4].

Market is classified into four structures including pure competition, monopoly, monopolistic competition and oligopoly based on the number of sellers, product differentiation, control over price and entry barriers. Industrial concentration is the most common measure of an industry's competitiveness or monopoly, and also an important criterion to identify market structure. Some experts have reported same similar results in measurement of China's retailing industrial concentration from the perspectives of regional market concentration and retailing activities concentration [5].

With the expansion of retail businesses and increase of industrial concentration, some large retailers will inevitably produce certain market power. Dobson proposes that a retailer's buyer power refers to the dominant retailer's ability to trade with the supplier in more favorable terms than other buyers or intended terms in normal competition conditions [6]. Clarke believes that buyer power refers to a retailer's ability to trade with the supplier in more competitive terms, including low intermediate goods price, marketing support, delayed payment and other competitive arrangements which are not available to small-sized retailers [7].

Large retailers not only collect entry fees under false pretenses but also take advantage of their buyer power to extend the payment term of accounts payable and possess substantial funds of the suppliers, resulting in financial strain in upstream manufacturers and suppliers and even influencing normal production and operation. In order to secure normal profits, manufacturers and suppliers have no choice but to raise product price and shift such cost to consumers, thus leading to loss of consumers' benefits. 
Sun Ru-pan et al. hold that large retailers' buyer power refers to their ability to control or influence supplier market variables, including price control, marketing support, delayed payment and adjustment to benefit distribution between buyer and seller, so that the retailer may seek more benefits in procurement activity with the aid of buyer power [8]. In the course of practical supply chain transactions, a retailer's buyer power is embodied in various forms including: the retailer procures discriminatory price discount from the supplier, the retailer collects various extra charges from the supplier, the retailer enters into a restrictive contract with the supplier, and the retailer expropriate substantial funds of the supplier for its own operation.

Market concentration is a common measure of buyer power, which measures the market structural concentration of the entire industry and the difference between the number of buyer/seller businesses and relative scale. In general, market concentration is positively correlated with buyer power. Therefore, it is generally believed that small-sized retailers do not have buyer power and are thus at a disadvantage in market competition.

\subsection{Supply Chain Efficiency}

Supply chain refers to the connection of all relevant persons or link of businesses before a commodity is delivered to the customer. It involves the whole process for a core enterprise to purchase raw materials, produce intermediates and finished products and eventually deliver products to customers via marketing channels through control of information, material and cash flows. It is a functional network chain structure integrating supplier, manufacturer, distributor, retailer and end user as a whole. The business philosophy of supply chain management is to pursue overall optimization of supply chain through inter-business collaboration from the perspective of customers. Successful supply chain management will operate to coordinate and integrate all activities in the supply chain and ultimately evolve into a seamless integrated process.

The value of information sharing among enterprises on the same supply chain is widely studied and recognized by scholars. Mohr believed trust and communication are very important in supply chain management because trust is the basis of information sharing and that good trust relation can reduce transaction and supervision cost, further improve the response speed of the whole supply chain, and eventually better the channel performance [9]. Lee et al. proposed an information-sharing value creating model for two-layer supply chain and believed that the demand information sharing among manufacturers can effectively reduce the inventory level and inventory cost and weaken the bullwhip effect [10].

Advanced information system effectively increases the accuracy and timeliness of information sharing, greatly improves the labor efficiency in goods receipt, inventory and ordering, lowers error rate and operational difficulty of employees and greatly reduces the total cost of inventory [11]. It also enables the enterprise to respond quickly to market changes, optimizes the allocation of resources, coordinates production activities and meets customers' personalized demands, thus reducing production and operating costs, improving product and service quality, and ultimately bringing economic profit and sustainable competitive advantage for enterprises [12].

Small-sized retailers are generally considered to have the following disadvantages: lack of funds, outdated information system and low-quality personnel and at a disadvantage in supply chain management [13].

\section{Research Design and Data Analysis}

In order to study the retailer's operation efficiency, we organized 20 students to carry out this survey. We designed 20 questions for the store owner, and totally recover 526 questionnaires, among which 511 ones are effective. The Survey covers urban districts and all suburbs. We research the surveyed shops based upon three indicators: scale of operation, mode of operation and business performance, which can be subdivided, as shown in Table 1.

Specifically, "average sales per unit area" refer to the annual sales amount per square meter of each shop, which can reflect the space utilization to some extent; "sales per person" refers to the annual sales amount of each person, which can reflect the labor efficiency or labor cost of a shop.

\subsection{The Basic Situation of Surveyed Shops}

Upon analysis of the questionnaires, we find that the independent retailers surveyed are mostly small, with a shop area less than $200 \mathrm{~m}^{2}$ and monthly sales amount less than RMB 100,000. They are generally family-run shops, of which the employees are mostly relatives or friends. The distribution of the surveyed shops is introduced as shown in Table 2. 
Table 1. Business indicators of surveyed shops.

\begin{tabular}{cr}
\hline Business indicators & Items \\
\hline $\begin{array}{c}\text { Scale of operation } \\
\text { Mode of operation }\end{array}$ & $\begin{array}{r}\text { Chain scale, monthly sales amount, business area, number of bar codes, total stocks and number of employees } \\
\text { Purchasing interval, settlement mode and average payment period }\end{array}$ \\
Business performance & Gross margin, average sales per unit area, sales per person and merchandise turnover \\
\hline
\end{tabular}

Table 2. The chain-degree distribution of surveyed shops.

\begin{tabular}{cccc}
\hline Type of shops & Degree of chain shop & Number of shops & Percentage of total (\%) \\
\hline Independent shop & Independent retailer & 336 & 65.8 \\
Low-degree chain shops & Chain shops $(\leq 5)$ & 78 & 15.3 \\
Medium-degree chain shops & Chain shops (6 - 19) & 53 & 10.4 \\
High-degree chain shops & Chain shops $(\geq 20)$ & 44 & 8.6 \\
\hline
\end{tabular}

The target market of the surveyed retail shops are surrounding residents. Hence, their sales products are consumer products, especially beverage, packaged food and liquor \& tobacco.

After analyzing the shops of different scales, we find that the monthly sales amount of independent retailers is mostly less than RMB 100,000; that of low- and medium-degree chain shops is more than RMB 300,000; and that of high-degree chain shops ranges from RMB 50,000 to RBM 200,000. There are few shops with a monthly sales amount of RMB 200,000 to RMB 300,000, as shown in Table 3.

According to different types of shops, sales distribution is shown in Figure 1.

\subsection{The Procurement of Surveyed Shops}

About $75 \%$ of fast moving consumer goods (FMCG) sold by large chain supermarkets in City S are purchased from manufacturer, 20\% from Tier I suppliers, and about 5\% from Tier II and Tier III suppliers. $90 \%$ - 95\% of goods in large chain convenience shops are directly provided by manufacturers, and only $5 \%$ - $10 \%$ (refrigerated and ready-to-eat foods) from other channels. Independent retailers, small in scale and scattered in locations, purchase most of goods from the wholesale markets and are at a disadvantage when bargaining with wholesalers, thus bearing a purchase cost higher than that of large chain shops. The result of questionnaires shows that the monthly cost (such as vehicles and personnel expenses) incurred by purchase from the wholesale markets is 6190.51 yuan on average, which is relatively high. In addition, it takes too much time and energy to purchase from the wholesale markets. All of these have increased the operation difficulties of shops.

This shows that: large chain retailers purchase most goods from manufacturers but just a few from distributors; small-sized retailers mainly purchase goods from distributors at all levels and wholesale markets and only a few from manufacturers directly. Why is there such a difference? The cost for direct contact, negotiation and channel maintenance with small and medium-sized retailers, a large group scattering nationwide, is very high, so distributors or wholesalers at all levels become a must. However, large chain retailers own logistics distribution systems, so supply agreements with the headquarters of such large retailers enable goods to be sold in their outlets.

According to the result of questionnaires, most independent retailers must pay in cash when purchasing, and just a few ones can purchase on credit. What is more, the payment period is very short. It reflects that wholesalers distrust independent retailers for financial security considerations. In addition, the profit sources of respondent shops are relatively single, mainly being the difference between purchase price and sales price, and other profit forms such as promotion or sales rebate are rare.

\subsection{The Operational Efficiency of Surveyed Shops}

After analyzing the operating efficiency of different shops, we find that the sales per unit area of independent retailers are less than those of all chain shops and with the increase of chain degree, the sales per unit area rise. However, independent retailers are better than chain shops in terms of sales per person and gross margin. "Sales 


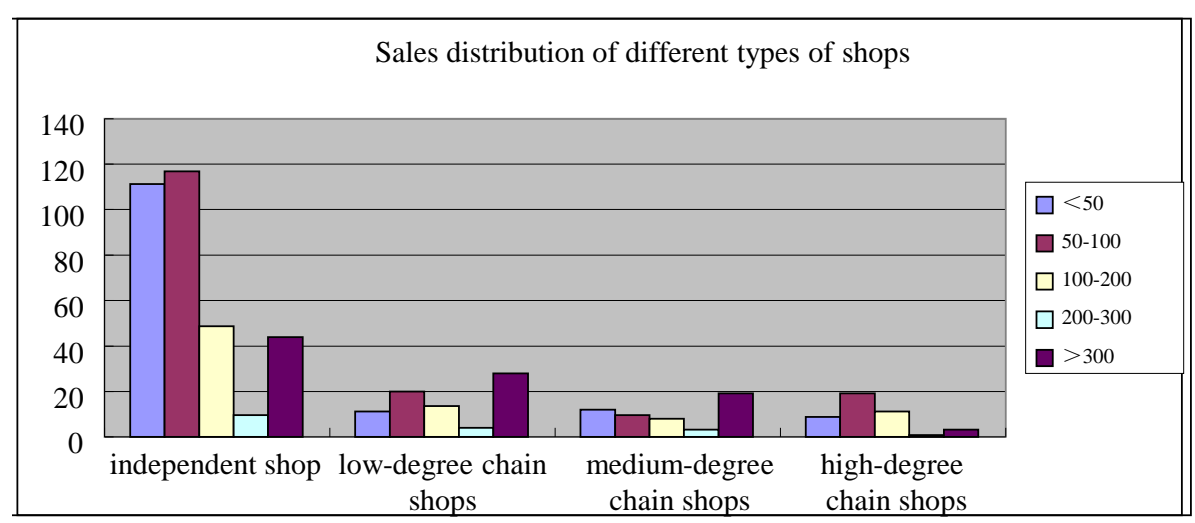

Figure 1. Degree of chain shops and Sales of surveyed shop.

Table 3. The sales distribution of surveyed shops.

\begin{tabular}{cccc}
\hline Scale of sales (thousand ¥/month) & Number of shops & Percentage of total (\%) & Cumulative percentage (\%) \\
\hline$>50$ & 143 & 28.0 & 28.0 \\
$50-100$ & 165 & 32.3 & 60.3 \\
$100-200$ & 84 & 16.4 & 76.7 \\
$200-300$ & 23 & 4.5 & 81.2 \\
$>300$ & 96 & 18.8 & 100.0 \\
\hline
\end{tabular}

per person” refers to the annual sales amount of each person, which can reflect the labor efficiency or labor cost of a shop. Operational efficiency of surveyed retail shops is shown in Table 4.

It can be seen that the shop space of independent retailers has not yet been efficiently and scientifically utilized. Chain operation can promote standardized and fine management of shops. Chain shops often increase their merchandise turnover with a slight drop in gross margin by reducing the unit price of products and increasing the sales volume. By this means, the sales per unit area can be increased.

We deem that the reason why the sales per person of independent retailers are higher than those of chain shops is as follows: independent retailers are mostly family-run shops; hence, their employees are willing to hold multiple jobs and work overtime; and the reason why the gross margin of independent retailers is higher than that of chain shops is that the product prices of independent retailers are slightly higher.

Of course, it is found in survey that the number of independent retailers is relatively smaller in commercially developed areas than that in commercially underdeveloped areas. This suggests that with the gradual perfection of commercial facilities, the competition on retail market is increasingly fierce, thus increasingly squeezing the living space of small-sized retailers. Regional distribution of independent shops is shown in Table 5.

\section{Conclusion and Enlightenment}

Through the survey and analysis of retail shops in City S, we find that the sales per unit area of independent retailers are very low and that the sales per person and gross margin are significantly higher than that of other chain shops. This shows that independent retailers lack of scientific and efficient utilization of in-shop space and fine management. The development from independent retailers to chain shops will help the standardization and fine management of these shops. As for the higher sales per person of independent retailers than that of the chain shops, we think the main reason may lie in that independent retailers are usually run by families. The incentive effect in such family-run business is very good, and every family member is willing to take more than one post and work for a long time.

The independent retailers, which are at a purchase disadvantage and mainly rely on the wholesale market or Tier III distributors, bear a higher purchase cost, hardly purchase high-quality goods at a low price and barely enjoy any privileges such as purchase on credit. As most of independent retailers are located outside developed 
Table 4. Operational efficiency of surveyed retail shops.

\begin{tabular}{ccccc}
\hline Type of shop & Average Sales per Unit Area & Sales per Person & Gross Profit Rate (\%) & $\begin{array}{c}\text { Merchandise Turnover } \\
\text { (Times/year) }\end{array}$ \\
\hline Independent retailer & 13818.7333 & 369260.9422 & 19.3962 & 11.3482 \\
Low-degree chain shops & 12850.6046 & 316282.1503 & 19.9138 & 12.4452 \\
Medium-degree chain shops & 15221.2068 & 239852.6298 & 17.9722 & 13.5474 \\
High-degree chain shops & 18506.3270 & 328304.5113 & 18.8750 & 16.5692 \\
\hline
\end{tabular}

Table 5. Regional distribution of independent shops.

\begin{tabular}{cccc}
\hline District & Number of independent shops & Total number of surveyed shops & Share (\%) \\
\hline Urban Area & 77 & 172 & 44.77 \\
Suburb A & 132 & 174 & 75.86 \\
Suburb B & 124 & 165 & 75.15
\end{tabular}

commercial areas, relatively high sales prices boost their gross margin, but lower turnover weaken their profitability and market competitiveness. In commercially underdeveloped conditions, relatively high gross margin and sales per person can provide some living space for independent retail shops. However, with the gradual perfection of commercial facilities, retail competition is becoming increasingly fierce and the living space for retailers is getting smaller and smaller.

\section{Acknowledgements}

This paper is supported by JNU Enterprise Development Institute Innovation Training Program of Guangdong Key Research Institute of Humanities and Social Sciences in Universities (Grant No. 2013CP007) and The Guangdong Nature Science Research Major Program (Grant No. 2014A030311022)

\section{References}

[1] Jin, B. (2003) Theory and Methodology of Measuring Enterprise Competitiveness. China Industrial Economics, 3, 513.

[2] Hu, Y.-Q. (2012) Comprehensive Appraisement of Enterprise Competitiveness Based on Statistical Analysis. China Business \& Trade, 8, 93-98.

[3] Zhang, F. (2012) Research on Assessment System of Supermarket Competitiveness. Business Economy, 9, 91-96.

[4] Bain, J.S. (1951) Relation of Profit Rate to Industry Concentration: American Manufacturing, 1936-1940. Quarterly Journal of Economics, 65, 293-324. http://dx.doi.org/10.2307/1882217

[5] Zhan, Y. and Nie, X. (2014) On the Influencing Factors of China's Retail Market Concentration. Statistics and Decision, 406, 85-88.

[6] Clarke, R., et al. (2002) Buyer Power and Competition in European Food Retailing. Edward Elgar, Cheltenham, Vol. 8, $15-23$.

[7] Dobson, P. and Inderst, R. (2007) Differential Buyer Power and the Waterbed Effect: Do Strong Buyers Benefit or Harm Consumers? European Competition Law Review, 28, 393-400.

[8] Sun, R.-P., Liu, W.-C. and Ren, J.-S. (2014) Research of Impact of Buyer Power of Retailers on the Relationship Quality between Retailers and Suppliers and Business Performance of Retailers-Theoretical Analysis and Research Proposition. Taxation and Economy, 2, 12-17.

[9] Mohr, J. and Nevin, J. (1990) Communication Strategies in Marketing Channels: A Theoretical Perspective. Journal of Marketing, 54, 36-51. http://dx.doi.org/10.2307/1251758

[10] Lee, H.L., So, K.T. and Tang, C.S. (2000) The Value of Information Sharing in a Two Level-Supply Chain. Management Science, 46, 626-643. http://dx.doi.org/10.1287/mnsc.46.5.626.12047

[11] Xiao, J.-H. and Wang, H.-C. (2014) The Mechanism of Value Creation by Supply Chain Information Systems: A Perspective of Information Sharing. Systems Engineering-Theory \& Practice, 34, 2862-2871. 
[12] Xie, L.-J. (2013) Distributor-Led Supply Chain Model and Implementation-Based on Comparison and Transformation of Similar Distribution Channels. Economic Theory and Business Management, 7, 103-112.

[13] Wang, N.-X., Zhong, W.-J. and Mei, S.-E. (2010) Information Technology, Core Capability and Firm Performance: An Empirical Study. Management Science, 2, 52-64. 